MASPONS I LABRós, Francesc de S.: Lo rondallaire. Tercera sèrie. Cuentos populars catalans. Edició a cura d'Albert Mestres. Biblioteca de Tots Colors 8. Valls: Cossetània Edicions, 2OI4, 333 p.

\title{
Lo rondallaire. Tercera sèrie. Cuentos populars catalans
}

Anna Llovera Juncà

Universitat de Lleida

La segona i darrera entrega de l'obra rondallística de Francesc de Sales Maspons i Labrós, que aplega el tercer volum de Lo rondallaire (I874) i els Cuentos populars catalans (I885), completa la tasca publicística endegada el 20Io per Cossetània Edicions amb l'aparició conjunta de la primera i la segona sèrie de Lo rondallaire. El volum conté vint-i-set rondalles i vint contes, més dos apèndixs: l'un amb vuit rondalles més («Rondalles disperses») i l'altre amb els quatre pròlegs de Maspons (més unes notes a l'últim d'aquests) corresponents als quatre volums publicats (I87I, I872, I874 i I885), l'últim dels quals, malgrat titular-se diferent, culmina aquesta col-lecció de textos folklòrics catalans. Tanquen el llibre dos índexs i un llistat de fonts de Maspons i Labrós, imprescindibles uns per capbussar-se ordenadament en l'univers rondallístic internacional i l'altre en la bibliografia de capçalera de l'autor.

No sé si l'editor, Albert Mestres, havia planificat incloure aquests apèndixs en el volum present, o bé si ho ha fet seguint la recomanació de Jaume Guiscafrè en la ressenya del llibre anterior: «Entenc que seria desitjable —i no me’n sé estalviar el suggeriment per si els editors no ho tenien previst- incorporar els pròlegs i la resta de paratextos que Maspons va incloure a cada lliurament i els índexs que propòs en un annex al segon volum d'aquesta nova edició». ${ }^{.}$El fet és que el llibre conté els pròlegs i un «Índex tipològic de rondalles per l'ordre ATU», un «Índex alfabètic de títols» i un llistat de «Fonts de F. Maspons i Labrós», realitzats, amb la col-laboració puntual d'Albert Mestres, per Josep Maria Pujol, a qui es dedica, pòstumament, aquest volum.

Francesc de Sales Maspons i Labrós (I840-I90I) ocupa un lloc preeminent en la nòmina de folkloristes catalans del segle xıx. Tot i no ser el primer a conrear «aquest gènero de literatura» (p. 274), sí que ho és a recopilar i publicar exclusivament rondalles de procedència oral. La majoria, confessa Maspons, tenen origen en una veu femenina d'Almenar, un poble a pocs quilòmetres de la Franja de Ponent. Albert Mestres, en la «Nota» inicial, destaca la importància de les dones en la transmissió de la tradició popular oral i evoca, sorprès, «l'inaudit protagonisme femení» (p. Io) de la majoria dels contes de Lo rondallaire. No em sé estar de referir breument el rol actiu i, a voltes, coratjós que Gaietà Vidal i de Valenciano, l'iniciador d'una literatura catalana de «tema rural», atorga també a algunes de les protagonistes dels relats que conformen La vida en lo camp. Quadros de costums catalanas (I867) —especialment destaquen Agustina (Confiansa en Dèu) i la pubilla (La Pubilla del Mas de Dalt). Em sembla que tot plegat respon a un imaginari tradicional i conservador, que atribueix a la dona la condició d'«àngel de la llar», és a dir, de gestora i protectora de la casa i de vetlladora dels costums i la moral.

I. GUISCAFRÈ, Jaume (2OI2): «Lo rondallaire». Estudis de Literatura Oral Popular / Studies in Oral Folk Literature, núm. I: I9I-I94.

Estudis de Literatura Oral Popular, núm. 4, 2OI5, I82-I85 | DOI: Io.I7345/elop20I5I82-I85 ISSN: 2OI4-7996 | http://revistes.urv.cat/index.php/elop 
Són precisament les tradicions allò que Maspons desitja mantenir amb la recopilació i la difusió de folklore: «Jo sols m'he proposat conservar, en lo que fos possible, los cuentos populars nostres tal com se conten i diuen, ja que amb la facilitat de comunicacions, amb lo més comunes que són entre uns territoris i altres, i amb la mudança de costums i de creències, que és d'allí a on naixen, se van los mateixos perdent» (p. 270). En l'imaginari literari del segle XIX, la tradició és un factor de primer ordre. Cal que tinguem present que l'efervescència nacional vuitcentista es forja damunt la idea d'una identitat (re)descoberta: la de l'ànima col-lectiva. Les lliçons herderianes de l'essència pàtria basada en un conjunt de símbols inherents a cada poble són assimilades per estudiosos dels costums i la història dels territoris. A Catalunya aquesta essència es vehicula a través d'un discurs ideològic conservador, que precisament ajuden a construir, entre d'altres, els folkloristes. Es tracta d'un sistema (un «subsistema» segons Llorenç Prats) ${ }^{2}$ simbòlic de la Renaixença que mitifica l'espai rural i el tipus d'organització social tradicional que s'hi associa, el familisme pairal, fortament en declivi a mitjan segle XIX (els relats suara esmentats de G. Vidal i de Valenciano en són el paradigma inicial). Per a Maspons, enmig d'aquest panorama de dissolució simbòlica, «les tradicions populars, [...] encara que no expressin amb tota fidelitat la veritat dels fets, són un escollit element per a la interpretació històrica, ja que revelen en tota sa nuesa les creències, los sentiments morals, les costums, los temors, les preocupacions, l'ideal poètic i artístic, en una paraula, tots los ressorts interns de la societat a què es refereixen» (p. 270). Concep la tradició, tanmateix, des d'una òptica ben curiosa: és «una però variable, mai fixa, ni quieta, com la mar, que essent la mateixa cada onada és distinta i variable, hermosa, igual en lo fondo, mes canviada i múltiple en la forma» (p. 280). Aquesta manca d'uniformitat és vista en positiu: «és verdadera mostra de riquesa d'imaginació en lo poble, al mateix temps que d'exuberància de sentiment i plenitud de vida i caràcter propis» (p. 28o). Parallelament, però, la fragmentarietat (benjaminiana) de la tradició apropa l'autor a la modernitat. Igual com l'experiència de desubicament, «enmig del tràfec que lo sigle porta, d'aqueixa contínua agitació en què es viu que ni moment de reposada dóna» (p. 275) respon a les coordenades de la irrupció d'un món nou: el de la més absoluta modernitat. Ja avisava Maspons que l'èxode rural cap a la ciutat era gairebé massiu. I que aquesta, cau del materialisme, no oferia el feix de tradicions (ni l'ordre ni la tranquil.litat) que es trobaven al camp. El que no explicava al lector era que, activant la tecla folklòrica, despertava una altra música: la del costumisme literari tradicionalista. Però això ja són figues d'un altre paner.

Amb la convicció ferma de la necessitat de conservar el material folklòric tradicional, i motivat per «Lo gran amor que porto a les coses de ma terra» (p. 269), Maspons inicia la tasca de recopilació de rondalles i contes (el que es coneix com a collecting materials) amb la intenció de prodesse et delectare: les rondalles poden servir per «moralisar i donar idees de verdader valor al poble. Quan no, ens portaran records i afectes sempre agradables, i ens faran despertar les fibres del cor a un benestar que ben necessari és en los temps de tràfec i agitació que avui dia corren, ajudant també a conèixer nostra terra, que tan i tan digna baix tots conceptes és d'ésser estudiada» (p. 284). Es plany, però, de la impossibilitat d'exercir de romeu

2. PRATS, Llorenç (I988): El mite de la tradició popular. Els orígens de l'interès per la cultura tradicional a la Catalunya del segle XIX. Barcelona: Edicions 62, p. I7O. 
de la pàtria peregrinant «de puig en puig, de freu en freu» ${ }^{3}$-almenys entre I872 i I874, anys de desenvolupament de la Tercera Guerra Carlina-, i es contenta de «cercar per les grans capitals. Sort que tothom hi fa via» (p. 287).

Per bé que hem de creure que les rondalles del present volum són ofertes sense la voluntat de construir un producte literari (Maspons en fa bandera sobretot al pròleg de I87I: «la veu mateixa del poble me les ha dictades i no he fet més, salvo en algunes vegades la forma, que transcriure-les de la mateixa manera com me les són dites», p. 269-270), no podem menystenir el regust literaturitzant que sovint contenen - i que traeixen, altrament, les mateixes paraules de Maspons. No em refereixo pas a una espècie d'amanerament estilístic, sinó a una depuració del llenguatge, una certa economia lingüística, que converteix els contes en uns relats àgils i frescos; en literatura, tanmateix. Hi contrasta, amb aquesta pretesa naturalitat volguda, la llengua dels pròlegs. És aquí, però, on discrepo lleugerament amb Albert Mestres, que hi veu una manca de qualitat de llengua a causa dels «tics lingüístics i retòrics indigestos» (p. 9). Jo hi veig, en canvi, unes fórmules lingüístiques cenyides a unes convencions certament retoritzants, però també allunyades en el temps, prou perquè tinguem present el context que les acollí. Ara, si la llengua és a voltes feixuga, les idees, minses, apareixen lleugeres i interessants.

Val la pena aturar-se en la definició que ofereix del conte català, molt lligat al caràcter de la nació, com ja havia enunciat Herder («nostres cuentos [...] no són més que l'expressió íntima idealisada del poble, tramesa a través dels sigles per la tradició oral», p. 270). Segons Maspons, sobre una base trípeda, que no és altra que la fórmula de Schlegel a propòsit de les influències culturals en la tradició neollatina, Catalunya ha escrit la pròpia Història. D’una banda, la tradició pagana li ha procurat l'antiguitat suficient per legitimar-se; de l'altra, el cristianisme hi ha imprès, damunt d'aquest substrat grecollatí, una pàtina de sublimitat, virtut i pau; i, finalment, la mitologia germànica ha proveït el conjunt de força i vigor. Aquest model, de «rostre ètnic complex», ${ }_{4}^{4}$ desemboca en uns relats que, «fills d'un poble actiu i emprenedor, valent, acostumat a tots los perills, cortès i cavaller i sobretot justicier i recte, mostren una valentia i grandesa a l'ensems que cavallerositat que pocs tenen» (p. 272). En efecte, el recull de contes i rondalles del present volum, igual que les de la primera i la segona entrega, narren històries senzilles de gran rendiment popular. Els personatges que hi desfilen responen a arquetips del patrimoni tradicional rondallístic: bruixes, follets, dimonis, animals personificats, tota la cort reial (prínceps, princeses, reis i reines), viudes, pobres, etc.

Amb tot, és la lectura dels quatre pròlegs de Francesc Maspons i Labrós a les tres sèries de Lo rondallaire i als Cuentos populars catalans la que proporciona una comprensió més profunda de l'avenç de l'interès pel folklore català al segle XIX. Si el I87I Maspons justifica la recopilació de material tradicional oral per un sentimentalisme romàntic (l'amor a les coses de la terra), el I872 aporta arguments més sòlids de l'interès per aquestes fonts (les tesis herderianes l'inspiren); el I874 se serveix del mètode comparatiu per tal d'explicar amb força precisió les semblances i diferències de la rondallística catalana amb, sobretot però no únicament,

3. Matheu, Francesc (I884): «Cansó del excursionista». Lo Renaixement. Butlletí mensual del Centre Catalanista d'Igualada, any I, núm. I (30 de juny de I884): II-I2.

4. MAGRIS, Claudio (20Io): Alfabets. Assaigs de literatura. Traduït de l'italià per Anna CASASSAS. Barcelona: Edicions de I984, p. 222. 
la d'altres països europeus; i, finalment, el I885 dóna mostres del nou rumb que adopta l'estudi del folklore als anys vuitanta: a poc a poc esdevé una disciplina etnogràfica i cultural que s'organitzarà en associacions i centres, i que rebrà el suport, un cop entrat el segle $\mathrm{xx}$, de les institucions. Es pot resumir aquesta evolució tot evocant les paraules (molt anteriors a l'encunyament, per cert, el I878, del concepte collecting materials per part de la Folklore Society) de l'amfitrió al jove protagonista de Der Nachsommer [Verano tardío] (1856), la gran novel-la de l'escriptor austríac Adalbert Stifter: «El recolectar precede siempre a la ciencia; esto no es sorprendente». I l'avisa del perill a què s'havia d'enfrontar l'estudi del folklore quan es va voler convertir en una disciplina científica: «pero sí es sorprendente que el afán de recolectar se apodere de los espíritus cuando va a aparecer una ciencia, aunque aún no se sepa qué contenidos tendrá ésta».5

És indubtable, més enllà de la literaturització latent de les rondalles i dels contes d'aquest recull, el valor antropològic, sociològic i històric del material que Francesc Maspons i Labrós recopilà i transcriví entre finals dels seixanta i la meitat dels vuitanta del segle XIX, i també l'interès dels pròlegs que l'acompanyen. Cal agrair, consegüentment, la tasca notable d'edició d'aquests textos feta per Albert Mestres, que els ofereix d'una forma molt ben disposada per a la lectura del públic actual, i agraïr també als membres de la unitat de recerca Arxiu de Folklore del Departament de Filologia Catalana de la Universitat Rovira i Virgili que estan al darrere d'aquesta iniciativa.

5. Stifter, Adalbert (2008): Verano tardío. Traducció de Carmen GaUger. València: PreTextos, p. I30. 